\title{
Invited Discussion on: Short-Scar Augmentation Mastopexy in Massive-Weight Loss Patients-Four-Step Surgical Principles for Reliable and Reproducible Results
}

\author{
Dennis J. Hurwitz ${ }^{1}$ (]
}

Received: 10 December 2019/Accepted: 10 December 2019/Published online: 20 December 2019

(C) Springer Science+Business Media, LLC, part of Springer Nature and International Society of Aesthetic Plastic Surgery 2019

Level of Evidence $V$ This journal requires that authors assign a level of evidence to each article. For a full description of these Evidence-Based Medicine ratings, please refer to the Table of Contents or the online Instructions to Authors www.springer.com/00266.

Over the past ten years, two Italian plastic surgeons have systematically addressed and successfully treated moderate to severe breast deformity in the massive weight loss (MWL) patient through polyurethane-covered silicone breast implant augmentation and a unique short scar mastopexy [1]. Wary of the high rate of delayed wound healing, implant malposition and recurrent parenchymal ptosis in this challenging patient population, they successfully innovated implant selection, autogenous implant support, parenchymal repositioning and short scar mastopexy.

With the aid of excellent drawings, they clearly explain a rather complex set of technical maneuvers. Based on impressive postoperative images and esthetic assessment data, their approach represents an incredible advance in the analysis and performance of complex breast enhancement surgery. Finally, they clearly present, along with an APS journal reference to their 2017 cadaver dissection and technique [2], enough information to instruct an experienced surgeon to attempt their technique.

The authors acknowledge that when there is adequate breast and neighboring tissue to shape the breasts, the most

Dennis J. Hurwitz

drhurwitz@hurwitzcenter.com;

http://www.hurwitzcenter.com

1 Pittsburgh, USA common approach for the MWL breast is an inverted " $\mathrm{T}$ " pattern mastopexy with augmentation using nearby flaps from tissue that would be excised during an upper body lift. They decry the lengthy scars, although these scars would otherwise be necessary for either the transverse upper body lift or J torsoplasty, which continues into an L brachioplasty (see Fig. 1) [3-5]. However, the authors show they can eliminate moderate or less lateral breast excess, through a well-projecting tight skin mastopexy and lateral breast roll with possible liposuction of the lateral chest.

Critical to their therapy are an understanding and treatment of three breast components consisting of: 1 . footprint; 2. skin envelop and nipple areolar complex; and 3. breast conus/gland. The current footprint is stabilized by an appropriately wide partial subpectoral muscle high projecting implant, with the IMF not violated. They prefer hyperprojected and large anatomical implants because they help in defining the footprint, especially in redraping the skin over the lower pole. Position stability and implant support are added through the anterior and posterior adherence of macrotexture polyurethane-covered anatomical implants. As these implants are unavailable in the USA and textured implants are out of favor, replication of this technique in my country would include a smooth-walled round implant.

Inferior pole projection follows the release of the pectoralis major muscle, but maintenance of the superficial fascia along the IMF and leaving the transverse entry incision open. Excess skin envelope and breast are taken with a full thickness midline inferior pole resection of skin and parenchyma, followed by the elevation of the parenchyma and tight closure of medial and lateral columns across the lower pole of the implant. Thus, they have avoided the waterfall deformity. 


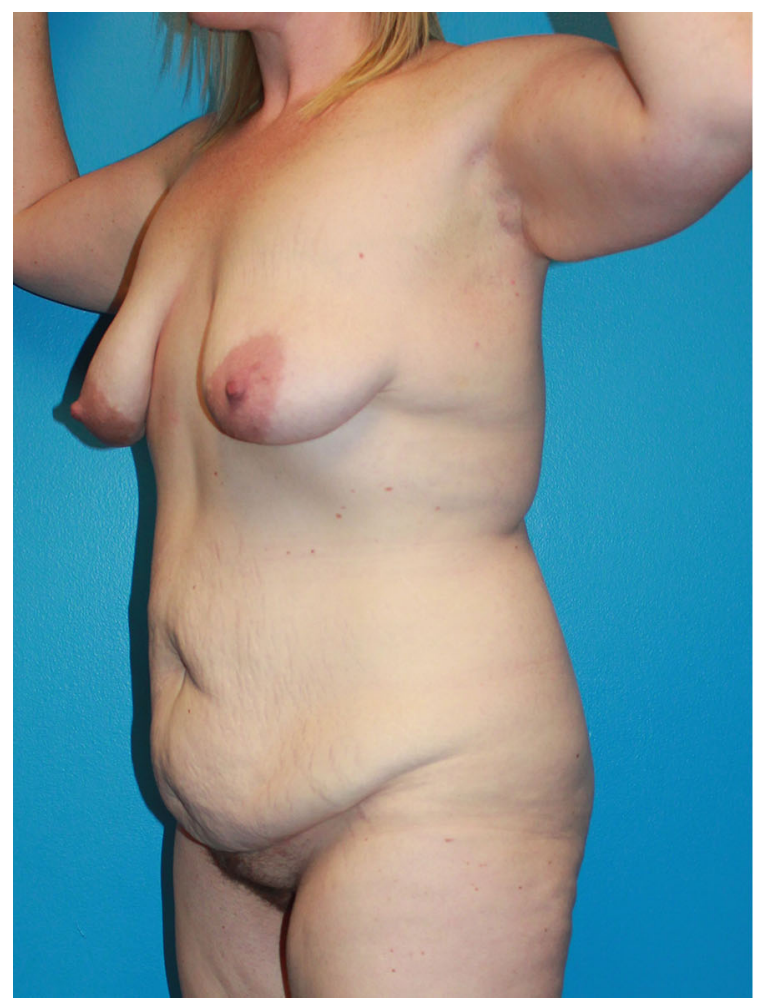

Fig. 1 Two-stage total body lift autologous breast reshaping in a 36-year-old with BMI of 28 after loosing $70 \mathrm{lbs}$ due to gastric bypass (left). The first stage was lipoabdominoplasty with oblique flankplasty. Two months later, she underwent Wise pattern mastopexy with

Access to the subpectoral pocket is through an infraareolar incision carried full thickness through the breast. A transverse incision is made through the pectoralis muscle with care taken to open the subpectoral space for the implant. Release of the infrapectoral attachments is carefully done to avoid violation of the inframammary fold and leave a bipedicle lower half of the pectoralis muscle which would be a supportive sling for the implant. Therefore, the pectoralis muscle and not the inferior breast pole is the retaining element.

With lower BMIs, there is no extra tissue for which to build the breasts, so an implant is needed for volume and projection. Between 2010 and 2018, they favorably picked healthy young patients with BMI less than $30 \mathrm{~kg} / \mathrm{m}^{2}$, smoke-free, good nutrition, weight stable for 6 months and young between 24 and 55 years. Indicative of their selectivity was only 40 consecutive cases over a 5 -year span.

There was no major complication. Their selected case presentations revealed full-size beautifully shaped breasts with proper NAC position, size and shape, and no sagging of the breasts or neighboring skin: all with only a circumventricular scar and at times a small lateral transverse extension. Independent surgeon esthetic analysis of the shape from photographs and patient Breast Q Surveys confirmed the high quality of the sampled results.

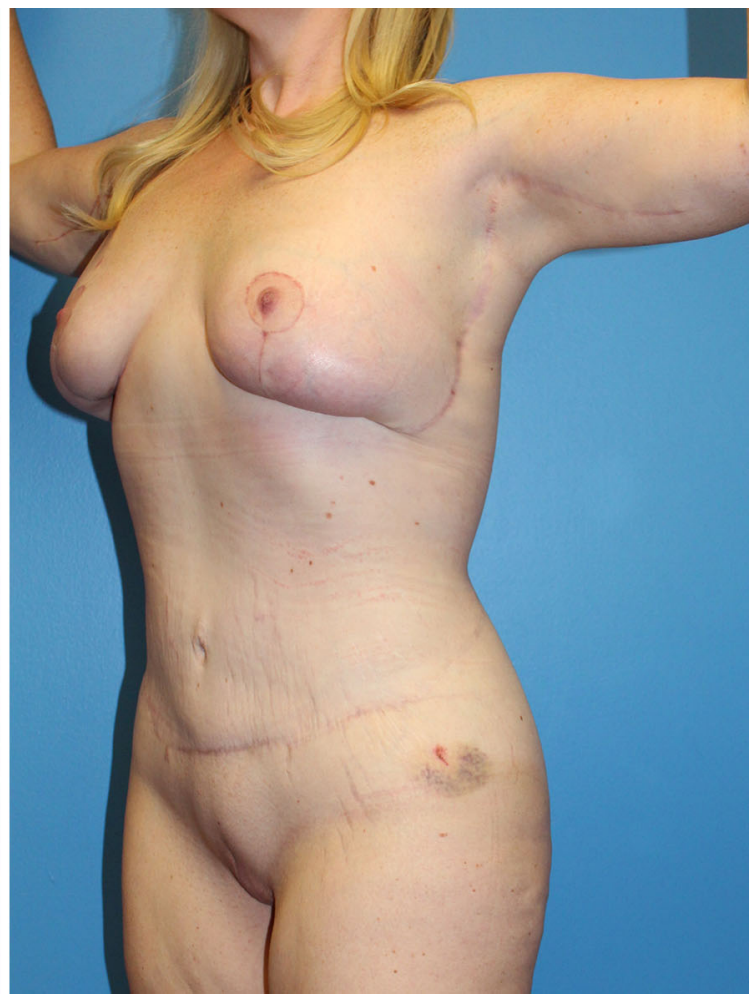

spiral flap reshaping of her breasts with the donor site of her flap being the $\mathrm{J}$ torsoplasty upper body lift, and accompanied by a limited $\mathrm{L}$ brachioplasty. The resulting TBL is seen one year later

To understand details of the inframammary fold and nearby dissection for implant space, one needs to read their 2017 Aesthetic Plastic Surgery reference. That being said, this discussant tried to replicate the procedure and found in his first patient that the lower pectoralis muscle was not as broadly draped as indicated in Fig. 1 anatomical drawing and preservation of the lower lateral fascia to cover the implant difficult.

To the credit of the authors, the pre- and postoperative photographs were taken with a consistent arm position being "at rest." The "at rest" position is akin to the response to military command whereby the soldier pulls the arm backward with the back of the hands resting on the flanks. That places the arms away from the breasts and lateral chest. However, that position causes posterior pull on the pectoralis muscle and overlying skin, thereby slightly improving the result. Furthermore, changes from other operations on the upper arms and flanks cannot be seen with that arm position.

The authors' technique does not easily include an upper body lift, which removes excess upper body skin, thereby tightening the epigastrium and lateral chest and, if needed, raise a low inframammary fold. If an upper body lift is needed, the scars must be extensive and coordinated with the breast reshaping. For this discussant combining 
augmentation mastopexy with liposuction of the lateral chest roll has necessitated short-term use of vacuum drains to avoid a seroma. The authors present no examples of circumareolar pattern mastopexy. In that case, this discussant is uncertain as to the extent of lower pole surgery.

Congratulations to the authors for a well-presented select series of artistically treated patients with implant augmentation mastopexy sagging breasts after MWL.

\section{Compliance with Ethical Standards}

Conflict of interest The author declares that he has no conflicts of interest to disclose.

Ethical Approval This article does not contain any studies with human participants or animals performed by any of the authors.

Informed Consent For this type of study, informed consent is not required.

\section{References}

1. Salgarello M, Visconti G (2019) Short-scar augmentation mastopexy in massive-weight loss patients: four-step surgical principles for reliable and reproducible results. Aesthetic Plast Surg. https://doi.org/10.1007/s00266-019-01540-0

2. Salgarello M, Visconti G (2017) Staying out of double-bubble and bottoming-out deformities in dual-plane breast augmentation: anatomical and clinical study. Aesthetic Plast Surg 41(5):999-1006

3. Hurwitz DJ, Agha-Mohammadi S (2006) Post bariatric surgery breast reshaping: the spiral flap. Ann Plast Surg 56(5):481-486

4. Clavijo-Alvarez JA, Hurwitz DJ (2012) J torsoplasty: a novel approach to avoid circumferential scars of the upper body lift. Plast Reconstr Surg 130(2):382e-383e

5. Hurwitz DJ, Holland SW (2006) The L brachioplasty: an innovative approach to correct excess tissue of the upper arm, axilla and lateral chest. Plast Reconstr Surg 117(2):403-411

Publisher's Note Springer Nature remains neutral with regard to jurisdictional claims in published maps and institutional affiliations. 